\title{
Oscillatory brain responses in spoken word production reflect lexical frequency and sentential constraint
}

\author{
Vitória Piai ${ }^{\mathrm{a}, \mathrm{b}, *}$, Ardi Roelofs $^{\mathrm{a}}$, Eric Maris ${ }^{\mathrm{a}}$ \\ ${ }^{a}$ Radboud University Nijmegen, Donders Institute for Brain, Cognition and Behaviour, Centre for Cognition, Montessorilaan 3 , \\ 6525 HR Nijmegen, the Netherlands \\ ${ }^{\mathrm{b}}$ International Max Planck Research School for Language Sciences, Wundtlaan 1, 6525 XD Nijmegen, the Netherlands
}

\section{A R T I C L E I N F O}

\section{Article history:}

Received 6 July 2013

Received in revised form

14 October 2013

Accepted 20 November 2013

Available online 28 November 2013

Keywords:

Alpha-beta

Lexical access

Oscillations

Picture naming

Theta

Lexical frequency

\begin{abstract}
A B S T R A C T
Two fundamental factors affecting the speed of spoken word production are lexical frequency and sentential constraint, but little is known about their timing and electrophysiological basis. In the present study, we investigated event-related potentials (ERPs) and oscillatory brain responses induced by these factors, using a task in which participants named pictures after reading sentences. Sentence contexts were either constraining or nonconstraining towards the final word, which was presented as a picture. Picture names varied in their frequency of occurrence in the language. Naming latencies and electrophysiological responses were examined as a function of context and lexical frequency. Lexical frequency is an index of our cumulative learning experience with words, so lexical-frequency effects most likely reflect access to memory representations for words. Pictures were named faster with constraining than nonconstraining contexts. Associated with this effect, starting around $400 \mathrm{~ms}$ pre-picture presentation, oscillatory power between 8 and $30 \mathrm{~Hz}$ was lower for constraining relative to nonconstraining contexts. Furthermore, pictures were named faster with high-frequency than low-frequency names, but only for nonconstraining contexts, suggesting differential ease of memory access as a function of sentential context. Associated with the lexical-frequency effect, starting around $500 \mathrm{~ms}$ pre-picture presentation, oscillatory power between 4 and $10 \mathrm{~Hz}$ was higher for high-frequency than for low-frequency names, but only for constraining contexts. Our results characterise electrophysiological responses associated with lexical frequency and sentential constraint in spoken word production, and point to new avenues for studying these fundamental factors in language production.
\end{abstract}

(c) 2013 Elsevier Ltd. All rights reserved.

\section{Introduction}

Speaking is one of our most highly exercised psychomotor skills (Levelt, 1989). Seemingly simple and effortless, the production of language relies not only on fast and accurate linguistic processes, such as the access of concepts and lexical representations in longterm memory (Indefrey \& Levelt, 2004; Levelt, Roelofs, \& Meyer, 1999), but also on precise motor preparation and execution (Hickok, 2012). Although psycholinguistic models have provided a detailed description of the cognitive architecture underlying language production (e.g., Caramazza, 1997; Dell, 1986; Levelt, 1989; Levelt et al., 1999; Roelofs, 1992, 1997), only recently electrophysiological markers of the postulated cognitive processes have been explored (e.g., Aristei, Melinger, \& Abdel Rahman, 2011;

\footnotetext{
* Correspondence to: Radboud University Nijmegen, Donders Institute for Brain, Cognition and Behaviour, Centre for Cognition, Spinoza Building B.01.05, Montessorilaan 3, 6525 HR Nijmegen, the Netherlands. Tel.: + 3124 3612635; fax: + 31243616066.

E-mail addresses: v.piai@donders.ru.nl (V. Piai),

a.roelofs@donders.ru.nl (A. Roelofs), e.maris@donders.ru.nl (E. Maris).
}

Eulitz, Hauk, \& Cohen, 2000; Strijkers, Costa, \& Thierry, 2010; Strijkers, Holcomb, \& Costa, 2011; see for review Ganushchak, Christoffels, \& Schiller, 2011). In the present study, we examined electrophysiological brain responses that are induced by two fundamental factors known to affect the planning of spoken words: lexical frequency and sentential constraint (e.g., Griffin \& Bock, 1998; Levelt, 1989).

Studies investigating lexical memory access in word production have made extensive use of the picture-naming paradigm. This line of investigation builds on the following two ideas: (1) the picture represents the concept to be expressed, and (2) producing the picture name requires access to lexical memory (i.e., lemmas and word forms, e.g., Levelt et al., 1999). A typical finding in picture-naming studies is that pictures whose names occur more frequently in the language (e.g., 'house' or 'dog') are named more quickly than pictures whose names occur less often in the language (e.g., 'spear' or 'globe'), a finding known as the lexical-frequency effect (e.g., Jescheniak \& Levelt, 1994; Oldfield \& Wingfield, 1965). Since word frequency is an index of our cumulative learning experience with words, the lexical-frequency 
effect is an important marker of long-term memory processes and likely reflects the access of lexical memory representations (e.g., Almeida, Finkbeiner, Knobel, \& Caramazza, 2007; Jescheniak \& Levelt, 1994; Kittredge, Dell, Verkuilen, \& Schwartz, 2008; Monaco, Abbott, \& Kahana, 2007; Ullman, 2001). Lexical access is assumed to consist of lexical selection and word-form encoding, which is further divided into morphological, phonological, and phonetic encoding (Levelt et al., 1999). All of these stages have been shown to be sensitive to frequency (e.g., Cholin, Dell, \& Levelt, 2011; Jescheniak \& Levelt, 1994; Piai, Roelofs, \& van der Meij, 2012; Roelofs, 1998; Strijkers et al., 2010). Lexical access takes place between about $200 \mathrm{~ms}$ post picture-onset and about $145 \mathrm{~ms}$ before articulation onset (Indefrey, 2011; Indefrey \& Levelt, 2004).

Everyday language production, however, usually involves sentences. The conceptual content of the message to be expressed (i.e., the semantic context) guides the access to memory and the activation of associated lexical candidates (e.g., Griffin \& Bock, 1998; Levelt, 1989; Levelt et al., 1999). Contextual cues constrain possible word candidates, thereby modulating the ease of lexical access and word production (Griffin \& Bock, 1998). Sentential constraint is a major determinant of fluency in spontaneous speech production (Levelt, 1989).

In the present study, participants read sentences that were either contextually constraining towards one final word (e.g., 'During the camping vacation, he was rarely in the') or not (e.g., 'During the day, he was rarely in the'). The final word of the sentence ('tent') was presented as a picture, which participants had to name. The lexical-frequency range of the picture names was varied (cf. Griffin \& Bock, 1998). In short, sentential constraint and lexical frequency were manipulated in order to investigate the electrophysiological signatures of these factors in spoken word production. Ideally, effects of lexical frequency and sentential constraint are assessed in spontaneous speech, but this is still no option for language production research. Griffin and Bock (1998) stated, "Clearly, one cannot directly assess either the redundancy of message specifications for word selection or the onset of wordproduction processes in spontaneous speech. Hence, the task used in this study consisted of naming pictures which were preceded by sentence frames. It thereby combined an estimate of the onset of processing for a particular picture name with a quantifiable manipulation of contextual constraint. The weakness of the task is that the sentence contexts were read by participants rather than being generated by them. Although reading sentence frames differs from generating messages, the product of comprehension should be similar to the conceptual representations that speakers normally develop." (p. 329).

Using this paradigm and measuring picture-naming response time (RT), Griffin and Bock (1998) observed that pictures following a constraining context were named more quickly than pictures following a nonconstraining context (for other studies using a similar task, see e.g., Badecker, Miozzo, \& Zanuttini, 1995; Blom \& Vasić, 2011; Caramazza \& Hillis, 1989; Gollan et al., 2011). Moreover, it was found that the lexical-frequency effect, commonly found with standard picture naming (e.g., Oldfield \& Wingfield, 1965), was only present in the naming latencies for pictures following nonconstraining contexts, but absent for pictures following constraining contexts. According to Griffin and Bock (1998), the activation of word-form representations in memory follows a logistic function with high-frequency words having a higher resting level of activation than low-frequency words. Sentential constraint is assumed to affect lexical (i.e., lemma) selection, which is supposed to have a bigger impact on lowfrequency than high-frequency words because of the logistic activation of word forms. However, since naming latencies were the only measure in that study, no information could be obtained about processes that occurred before the picture was presented.
In particular, it is unclear whether the interaction between lexical frequency and sentential constraint occurred after picture presentation onset (Griffin \& Bock, 1998) or already before it. That is, the narrower context may have given lexical access a head start (i.e., access may have started earlier in time, possibly already before picture onset) rather than affecting activation levels of word forms after picture onset, as Griffin and Bock (1998) assumed. In the present study, we investigated the effects of lexical frequency and sentential constraint on spoken word production using the electroencephalogram (EEG), which allows us to investigate cognitive processes as they unfold in time, revealing whether or not effects occur already before picture presentation onset.

Electrophysiological studies of language production have mainly focused on single-word production using event-related potentials (ERPs, see for a recent review Ganushchak et al., 2011). In contrast, in the present study, we focus on brain oscillations. Oscillations are a common type of activity generated by neuronal populations (Buzsáki, 2006). Depending on the size of these populations and their degree of synchronisation, this neuronal activity can be recorded with EEG (Nunez \& Srinivasan, 2006). This oscillatory activity is typically categorised into different frequency bands. Different cognitive functions have been associated with frequency-specific changes in oscillatory power (e.g., Engel \& Fries, 2010; Hanslmayr, Staudigl, \& Fellner, 2012; Jensen \& Mazaheri, 2010; Khader \& Rösler, 2011; Van Ede, de Lange, Jensen, \& Maris, 2011).

Very little is known about oscillations in language production, especially with overt vocal responses (Ewald, Aristei, Nolte, \& Abdel-Rahman, 2012; Laaksonen, Kujala, Hultén, Liljeström, \& Salmelin, 2012; Piai et al., 2012; Piai, Roelofs, Jensen, Schoffelen, \& Bonnefond, 2013). The few studies that did examine oscillations addressed diverse questions, using different paradigms and experimental manipulations. Therefore, no clear pattern has yet emerged characterising the oscillatory components associated with cognitive processes underlying language production.

Importantly, it has been shown that ERPs and oscillations can be complementary in the type of information they provide (e.g., Bastiaansen \& Hagoort, 2003; Chen et al., 2012; Davidson \& Indefrey, 2007; Donner \& Siegel, 2011; Laaksonen et al., 2012). Yet, at present, almost all existing knowledge of the electrophysiology of language production is based on ERPs only (e.g., Aristeiet al., 2011; Eulitz et al., 2000; Laganaro et al., 2009; Laganaro, Valente, \& Perret, 2012; Strijkers et al., 2010, 2011; see for review Ganushchak et al., 2011). A characterisation of oscillatory activity has been fruitful in other cognitive domains, such as memory and motor control (see for reviews Engel, Fries, \& Singer, 2001; Schroeder \& Lakatos, 2009; Uhlhaas, Roux, Rodriguez, Rotarska-Jagiela, \& Singer, 2010). By characterising the oscillatory activity underlying spoken word production, language production can be understood in a broader context of how cognitive processes are implemented in the brain, possibly providing ways to link findings from the language production literature with other domains of cognition.

In other tasks not involving language production, oscillatory brain responses have been better identified and some of these findings are relevant for the present study (i.e., language comprehension, long-term memory access, and motor preparation). In particular, theta-band (4-8 Hz) activity has often been observed in relation to memory processes (e.g., Jacobs, Hwang, Curran, \& Kahana, 2006; Khader \& Rösler, 2011; see for reviews Düzel, Penny, \& Burgess, 2010; Klimesch, 1999; Nyhus \& Curran, 2010), also involving the retrieval of lexical-semantic information during language comprehension (e.g., Bastiaansen, van der Linden, Ter Keurs, Dijkstra, \& Hagoort, 2005; Bastiaansen, Oostenveld, Jensen, \& Hagoort, 2008). Oscillations in the alpha band $(8-15 \mathrm{~Hz})$ have been associated with a variety of cognitive processes, including 
semantic processing and memory (e.g., Hanslmayr et al., 2012; Klimesch, 1997; Klimesch, Doppelmayr, Pachinger, \& Russegger, 1997; Röhm, Klimesch, Haider, \& Doppelmayr, 2001; see for a review Klimesch, 1999). However, in language comprehension, the involvement of alpha-band activity is less clear (e.g., Bastiaansen et al., 2005, 2008; Röhm et al., 2001; Willems, Oostenveld, \& Hagoort, 2008; but see Mellem, Bastiaansen, Pilgrim, Medvedev, \& Friedman, 2012). Finally, over the broader frequency range 8$30 \mathrm{~Hz}$ (encompassing both the $8-15 \mathrm{~Hz}$ alpha and the $15-30 \mathrm{~Hz}$ beta band), decreases in oscillatory power are reliably observed in relation to motor preparation and execution (e.g., Alegre et al., 2004; McFarland, Miner, Vaughan, \& Wolpaw, 2000; Neuper, Wörtz, \& Pfurtscheller, 2006, see for a review Cheyne, 2013), although they are not restricted to the motor system (Van Ede et al., 2011; Van Ede, de Lange, \& Maris, 2012).

Our expectations for the present study were as follows. Regarding the behavioural responses, pictures in constraining contexts should be named more quickly than in nonconstraining contexts (Griffin \& Bock, 1998). Moreover, in a nonconstraining context, participants cannot know in advance which picture will be presented. As a consequence, the picture name has to be retrieved from memory upon picture presentation, leading to a lexical-frequency effect in the naming latencies. In contrast, in a constraining context, participants are likely to predict the final word of the sentence (e.g., Dikker \& Pylkkänen, 2013), which is the picture they have to name. Presumably, they can already start the access of the picture name before the picture is presented. Therefore, we expected that the lexical-frequency effect in the naming latencies would be much smaller as compared to the lexical-frequency effect in nonconstraining context sentences, replicating Griffin and Bock (1998). Regarding the neuronal data, we expected lexical access to be indexed by modulations in the theta or the alpha band, and therefore we predicted an effect of lexical frequency on oscillatory power in these frequency bands. In particular, with a constraining context, in which the lexical item can already be retrieved prior to picture presentation, the power modulations should be observed before the picture is encountered (contrary to the assumption of Griffin \& Bock, 1998). Furthermore, when the lexical item is retrieved, its articulatory programme can also be prepared. Since we expected motor preparation for speaking to be indexed by modulations in the alpha and the beta band, we predicted an effect of contextual constraint (constraining versus nonconstraining sentential context) on oscillatory power in these frequency bands.

\section{Method}

\subsection{Participants}

Seventeen native speakers of Dutch (8 male), all young adults, voluntarily participated in the experiment for monetary compensation or for course credits. The datasets of two female participants were not analysed due to poor blinkingspeech coordination (i.e., the preparation to speak was often accompanied by eye blinks), resulting in the loss of a large number of trials. Thus, the complete dataset analysed and reported below comprised 15 participants. All participants were right-handed, with normal or corrected-to-normal vision, and no history of neurological or language deficits. Participants gave written consent after they were completely informed about the nature of the study. The experiment was approved by the Ethics Committee for Behavioural Research of the Social Sciences Faculty at Radboud University Nijmegen and followed the Declaration of Helsinki (World Medical Association 1964, 2008)

\subsection{Materials}

One hundred and thirty line drawings of common objects were taken from the picture database of the International Picture-Naming Project (Szekely et al., 2004). For each picture, two sets of sentences were constructed for which the picture names were the last word of the sentences. In one set, sentences were constructed such that the picture name was highly expected (constraining context), whereas in the other set, no word was expected as the final word of the sentence (nonconstraining context). There was no significant difference in sentence length between conditions (mean number of words, constraining: 8.36, nonconstraining: 8.29; range: $6-13$ ), $p=0.677$. Where possible, the sentences associated with the same target picture differed only in a few words between conditions. In $74 \%$ of the sentences, a function word (a definite or indefinite article, or a possessive pronoun) preceded the target picture name in the sentence. In the remaining sentences, the word preceding the picture name was always an adjective, and care was taken that the adjective used was either the same across the two sentences, or matched for frequency and number of letters. The materials can be obtained on request.

\subsubsection{Pre-test of the sentence frames}

To verify that the sentences in the constraining and nonconstraining contexts differed in the degree of expectancy for the final word (i.e., cloze probability; Taylor, 1953), a pre-test was conducted with 28 native speakers of Dutch ( 5 male). From the 260 sentences, we constructed two main lists, each containing 65 sentences from each context condition. All sentences were presented up to, but excluding, the last word of the sentence, which was the picture name. Participants received the sentences via e-mail and were instructed to read the sentences one at a time and to provide three completions (nouns) for each incomplete sentence. Two types of cloze probability were derived (Griffin \& Bock, 1998). The first-response probability was calculated based on the proportion of participants who used the target picturename as their first completion. The overall probability was calculated as the proportion of participants who used the target picture-name as one of their completions. Four pictures were excluded from the materials because the constraining sentences associated with them had low cloze probability. The mean cloze probabilities of the remaining 126 pictures for the constraining and nonconstraining contexts are shown in Table 1 . The sentences in the nonconstraining condition did not have a high-cloze probability for any word.

\subsubsection{Lexical-frequency analysis}

To examine the effect of lexical frequency, we split the materials into a lower and a higher frequency set of picture names. For that, the log lemma frequency of the picture names was retrieved from CELEX (Baayen, Piepenbrock, \& van Rijn, 1993). Next, by taking the median log lexical frequency of all picture names (3.1/million), they were split into a low (mean log frequency $=2.3 /$ million) and high (mean $\log$ frequency $=4.3 /$ million) frequency conditions, on which subsequent analyses were conducted. Moreover, Two measures of phonological complexity were determined: picture-name length in number of phonemes and the presence of consonant clusters. Words in the high- and low-frequency conditions did not differ in the proportion of consonant clusters (initial word-position: $27 \%$ and $14 \%$; middle position: $0 \%$ and $3 \%$; final position: $17 \%$ and $8 \%$ respectively; all $p s>.08$ ), but they were on average half a phoneme longer in the low-frequency than in the high-frequency condition, $p=0.019$ (see Supplement for additional analyses). Name agreement measures were obtained for 120 of our 126 pictures from Severens, Van

Table 1

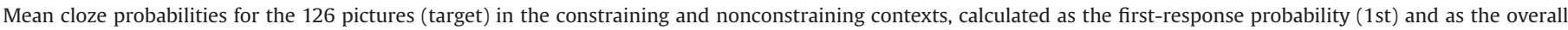
probability (Overall), and example sentence frames.

\begin{tabular}{|c|c|c|c|c|}
\hline Context & $1 \mathrm{st}$ & Overall & Example sentence frame & Target \\
\hline Constraining & 76 & 90 & $\begin{array}{l}\text { Tijdens de kampeervakantie zat hij nauwelijks in de } \\
\text { During the camping vacation, he was rarely in the } \\
\text { Om cellen te kunnen zien, gebruikt men een } \\
\text { In order to see cells, one uses a }\end{array}$ & $\begin{array}{l}\text { Tent } \\
\text { Tent } \\
\text { Microscoop } \\
\text { Microscope }\end{array}$ \\
\hline Nonconstraining & 1 & 4 & $\begin{array}{l}\text { Gedurende de dag was hij nauwelijks in de } \\
\text { During the day, he was rarely in the } \\
\text { Om dit te kunnen zien, gebruikt men een } \\
\text { In order to see this, one uses a }\end{array}$ & $\begin{array}{l}\text { Tent } \\
\text { Tent } \\
\text { Microscoop } \\
\text { Microscope }\end{array}$ \\
\hline
\end{tabular}


Lommel, Ratinckx, and Hartsuiker (2005). For the remaining six pictures, 15 young Dutch adults were asked to name the pictures using one word. The number of names given to the pictures and their $H$-statistic were calculated following Severens et al. Pictures in the high- and low-frequency conditions did not differ in the number of names given (on average 2.9 and 2.8 , respectively, $p=0.589$ ), nor in the $H$-statistic (on average 0.68 and 0.64 , respectively, $t(124)<1$ ). To evaluate whether the recognition of the experimental pictures was independent of the lexical frequency of their names, a picture recognition task was used (e.g., Piai et al., 2012). Twelve native speakers of Dutch (1 male), none of which took part in the experiment proper, performed the picture recognition task. In addition to the experimental pictures, 126 filler pictures were selected from the same picture gallery. Participants' task was to indicate with a button press whether a presented written word and a presented object referred to the same entity (right button) or not (left button). For the experimental pictures, the word and the picture always referred to the same entity; the filler pictures were always preceded by a different word. All 252 trials were randomly presented with one unique randomisation per participant. A trial started with the presentation of a written word in the centre of the screen for $500 \mathrm{~ms}$, followed by a black screen for $500 \mathrm{~ms}$, followed by a picture presented in the centre of the screen for $1 \mathrm{~s}$. Only the response times (RTs) of the experimental pictures with correct verification were analysed (mean error percentage $=4.8$, equally distributed across conditions, $p>0.05$ ). Mean RTs were $501 \mathrm{~ms}$ for the high-frequency and $500 \mathrm{~ms}$ for the low-frequency items. No difference in ease of recognition was observed, $t(11)<1$. Finally, the objective visual-complexity norms of the pictures (Szekely et al., 2004) did not differ between high-frequency and low-frequency items, $t(124)<1$. Note that word age of acquisition - the age at which a word is first learned - tends to correlate with lexical frequency (see for discussion Bonin, Barry, Méot, \& Chalard, 2004). To control for this variable, Dutch norms were obtained for 103 of our 126 picture names from Moors et al. (2013). Mean age of acquisition was similar for the words in the high- and low-frequency conditions (5.1 and 5.0 respectively, $t(98)<1$ ). Although norms for 23 words were not included in the analysis, there is no a prior reason to assume that these remaining 23 words would differ from the 103 included words. Thus, given that the pictures are recognised equally fast in the two lexical-frequency conditions and they do not differ in the degree of visual or phonological complexity, nor in word age of acquisition, any differences observed across them, either in the naming latencies or in the EEG, should be attributed to the lexical-frequency effect, indicating access to long-term memory.

\subsection{Design}

In the experimental lists, all 126 target pictures were included, once associated with a constraining sentence and once with a nonconstraining sentence. All 252 sentences were pseudo-randomised with one unique list per participant using mix (Van Casteren \& Davis, 2006). The randomisation was constrained such that (1) there were at least 20 trials intervening between the two presentations of a given picture and (2) the same condition appeared at most in three consecutive trials. Moreover, 48 comprehension questions were interleaved randomly between the experimental sentences.

\subsection{Procedure}

Participants were tested individually in an electrically and acoustically shielded room. The stimuli subtended $1^{\circ}-1.3^{\circ}$ visual angle when projected on the screen placed $90 \mathrm{~cm}$ in front of the participants. Before the experiment, participants were instructed to keep fixation on the centre of the screen, to minimise (head) movement during the experimental blocks, to keep their lips apart when not producing a word, and to blink only at the blinking moments. These instructions were practised with 12 trials for which a fixation cross was displayed for $500 \mathrm{~ms}$, followed by a picture to be named for $2 \mathrm{~s}$, followed by $* * *$ for $2 \mathrm{~s}$, indicating that participants were allowed to blink. The practice was repeated in case a participant did not conform to the instructions. Next, a familiarisation phase was conducted during which participants were shown all experimental pictures one by one on the screen following the same trial structure as the practice. After $600 \mathrm{~ms}$ of picture presentation, the target picture name appeared on top of the picture. Participants were instructed to read the picture name aloud and to use the respective labels in the remainder of the experiment. The experiment proper followed. A trial began with a fixation cross presented for $500 \mathrm{~ms}$. The first word of the sentence followed Each word of the sentence was presented for $300 \mathrm{~ms}$, interleaved with a blank screen for $300 \mathrm{~ms}$. The picture was presented for $2 \mathrm{~s}$, followed by ${ }^{* * * *}$ for $2 \mathrm{~s}$, which was the blinking interval. Participants were instructed to read the sentences attentively and to name the pictures. Moreover, they were told to respond to the comprehension questions by saying 'yes' or 'no'. The 252 experimental trials were divided into 12 blocks with self-paced breaks in between. The whole session, including participant preparation, lasted approximately $1 \mathrm{~h}$ and $15 \mathrm{~min}$.

\subsection{Data acquisition}

A microphone in the shielded room was connected to a PC, in which the Presentation Software (Neurobehavioral Systems) controlled stimulus presentation and the recording of the vocal responses. EEG was recorded from 26 scalp electrodes mounted in an elastic cap, positioned according to the international 10-20 system, using the Acticap system, amplified with BrainAmps DC amplifiers ( $500 \mathrm{~Hz}$ sampling, $0.016-100 \mathrm{~Hz}$ band-pass). Each electrode was referenced on-line to the left mastoid and re-referenced off-line to averaged mastoids. The electrooculogram was recorded horizontally from the electrodes placed on the left and right temples and vertically from the electrodes positioned below and above the left eye. Surface electromyogram was recorded from the orbicularis oris muscle with two electrodes placed on the left upper and right lower corner of the mouth. Electrode impedance was kept below $8 \mathrm{k} \Omega$.

\subsection{Statistical analysis of naming latencies}

The experimenter evaluated participants' vocal responses in real time. Responses containing a disfluency, a wrong pronunciation of the word, or a wrong response word were coded as errors and the corresponding trials were excluded from all subsequent analyses. Errors were not analysed due to their low occurrence (3.8\%). We submitted naming latencies to by-participant $\left(F_{1}\right)$ and by-item $\left(F_{2}\right)$ analyses of variance with context (constraining and nonconstraining) and lexical frequency (high and low) as independent variables. Moreover, we analysed the distribution of the naming latencies by means of Vincentising (Ratcliff, 1979). For that, we rank-ordered the naming latencies for each participant and context type separately and divided them into $20 \%$ quantiles. We then averaged the quantiles across participants and context type.

\subsection{EEG preprocessing}

The EEG analyses were performed using FieldTrip (Oostenveld, Fries, Maris, \& Schoffelen, 2011), an open-source Matlab toolbox. All trials excluded from the naming latencies analysis were also excluded from the EEG analysis. Trials were cut from the raw data using two schemes, one centred on the time of picture presentation (picture segments), and the other starting at the presentation of a word (word segments). In the first scheme, picture segments were cut from $800 \mathrm{~ms}$ pre-picture onset (thus, including the last written word of the sentence) to $800 \mathrm{~ms}$ post-picture onset. In the second scheme, word segments were cut from the presentation of the first word of the sentence until $1.2 \mathrm{~s}$ (thus, including the first two words of the sentence). The same scheme was also used for the third-to-last word of the sentence.

We examined all epochs individually and rejected those that contained eye movements, electrode drifting, and muscular artefacts in which mouth EMG showed activity above baseline before participants responded. In total, we rejected $11 \%$ of the data, equally distributed across conditions, $t(14)<1$. Four peripheral channels were excluded (F7, F8, T7, T8) due to a high noise level. After artefact rejection, an average of 107 segments per participant remained in each context condition, and an average of 54 segments in each context-by-lexical-frequency condition.

\subsection{Time-frequency representations of oscillatory power around picture presentation}

TFRs of power were computed for the picture segments time-locked to picture presentation onset, ranging from $600 \mathrm{~ms}$ pre-picture to $600 \mathrm{~ms}$ post-picture onset, at frequencies ranging between 2 and $30 \mathrm{~Hz}$, using a sliding time window of three cycles advanced in steps of $10 \mathrm{~ms}$ and of $1 \mathrm{~Hz}$. The data in each time window was multiplied with a Hanning taper, followed by a Fourier transform. For the comparison between constraining and nonconstraining contexts, per participant, the TFRs were averaged over trials for each context type. For the comparison between the lexical frequency conditions, per participant, the TFRs were averaged over trials for each combination of context type and lexical frequency. Finally, we addressed the evolution of power changes in the course of the sentence for the context effect by estimating spectral power for the word segments in the same way as for the picture segments. No effects were observed in the gamma band (30$100 \mathrm{~Hz}$ ) and, therefore, we do not specify those analyses here.

\subsection{Event-related potentials around picture presentation}

Prior to time-locked averaging, single trials were filtered with a lowpass zerophase shift Butterworth filter with a cutoff frequency of $20 \mathrm{~Hz}$. Trials with naming latencies shorter than $550 \mathrm{~ms}$ were excluded to avoid contamination of the ERPs with articulation artefacts.

The artefact-free epochs were further segmented to last until $500 \mathrm{~ms}$ after picture presentation onset. The direct current (DC) component was removed from the data by subtracting the average potential of the whole epoch. Moreover, single waveforms were baseline-corrected using the average EEG activity in the interval 
between $200 \mathrm{~ms}$ prior to the presentation of the last word of the sentence until the onset of the last word (i.e., -800 to $-600 \mathrm{~ms}$ pre-picture onset). For the statistical analyses of the context effect, averaged ERPs were computed per participant over trials for each context type. For the comparison between the lexical frequency conditions, per participant, the ERPs were averaged over trials for each combination of context type and lexical frequency.

\subsection{Statistical analysis}

The sentential-context and lexical-frequency effects were statistically evaluated using a non-parametric cluster-based permutation test (Maris \& Oostenveld, 2007). We briefly describe the method and the parameters used in the analysis but refer to the original article for a detailed description. In essence, this statistical test is timefrequency-, and channel-uninformed. That is, the full time-frequency-channel space was blindly scanned for adjacent time points, frequencies, and channels that exhibit a similar difference across conditions. For the ERPs, the search space was formed by time points and channels only. Crucially, the false alarm rate of this nonparametric cluster-based permutation test is controlled at the alpha level (in this study, 0.05) that is used for determining statistical significance (see Maris \& Oostenveld, 2007).

The statistical tests included all 22 analysed channels and time points (i.e., the full time and channel space). Channels were set to have, on average, 3.8 neighbours. For the TFRs, frequencies between 2 and $30 \mathrm{~Hz}$ were entered into the analysis (i.e., the full frequency space). The adjacent time-frequency-channel points (TFRs) or time-channel points (ERPs) were clustered based on a pre-determined $t$-value threshold of \pm 2.14 (i.e., an alpha-level of 0.05 with 14 degrees of freedom). To calculate the permutation $p$-value, we used the Monte Carlo method involving 1000 random permutations. A Monte Carlo cluster $p$-value below 5\% (two-tailed testing) was considered significant.

The following tests were conducted. For the picture segments (from the last word of the sentence until $600 \mathrm{~ms}$ after picture onset), the context effect was evaluated by comparing the constraining and nonconstraining context types. For the word segments, the context effect was examined with one non-parametric permutation test at each word, starting with word onset and lasting for $600 \mathrm{~ms}$. The lexical-frequency effect was evaluated by comparing the high- and the lowfrequency conditions for each context type separately.

\section{Results}

3.1. Sentential context modulates naming latencies, ERPS, and prepicture alpha- and beta-band power

Fig. 1 (left panel) shows the mean naming latencies and the cumulative distribution of the naming latencies as a function of context. Naming responses were faster in the constraining than in the nonconstraining context, $F_{1}(1,14)=145.3, p<0.001, F_{2}(1,124)=$
269.5, $p<0.001$. The cumulative RT distribution shows that the context effect is the result of a shift of the entire curve as a function of context. This means that, regardless of how fast participants named the pictures, the naming responses were always slower when the context was not constraining towards the picture name, strongly indicating that the context aided the word planning process.

Grand-average ERPs for the context and lexical-frequency conditions are shown in Fig. 2, averaged over five representative channels (coloured red in the montage depicted on the left side). For statistical evaluation, we used a cluster-based permutation test (Maris \& Oostenveld, 2007), which controls the false alarm rate in the context of the very large number of (channel, time)-pairs at which the effect of interest is evaluated. This test, which was time and channel uninformed, revealed a statistically significant difference between the constraining and nonconstraining contexts

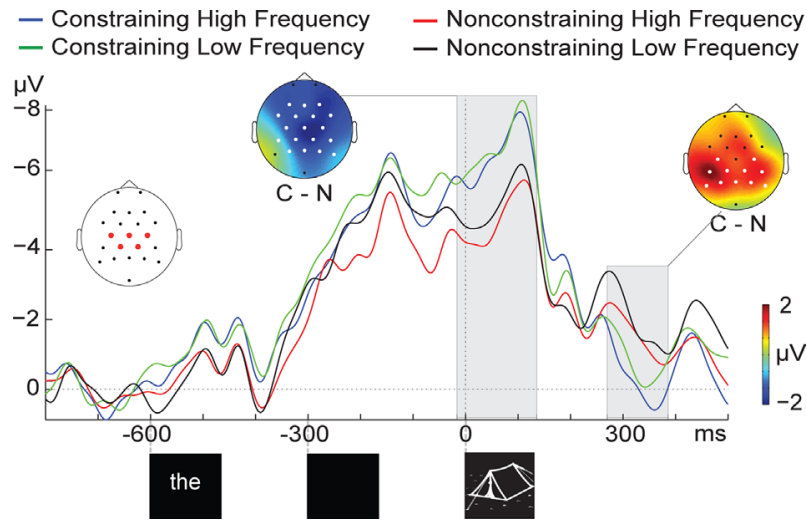

Fig. 2. Event-related potentials (ERPs) to the last word of the sentence and to the picture as a function of sentential context and lexical frequency. The presented ERPs are the average over the five representative channels highlighted in red in the montage depicted on the left side. The scalp distributions of the sentential-context effect (constraining vs. nonconstraining) are shown averaged over the significant time windows (grey shaded areas) of -16 to $136 \mathrm{~ms}$ (left) and 270-386 ms (right) The channels participating in the significant clusters are highlighted in white in the topographical maps. The boxes below the figure exemplify the events in the trial $C=$ constraining; $N=$ nonconstraining
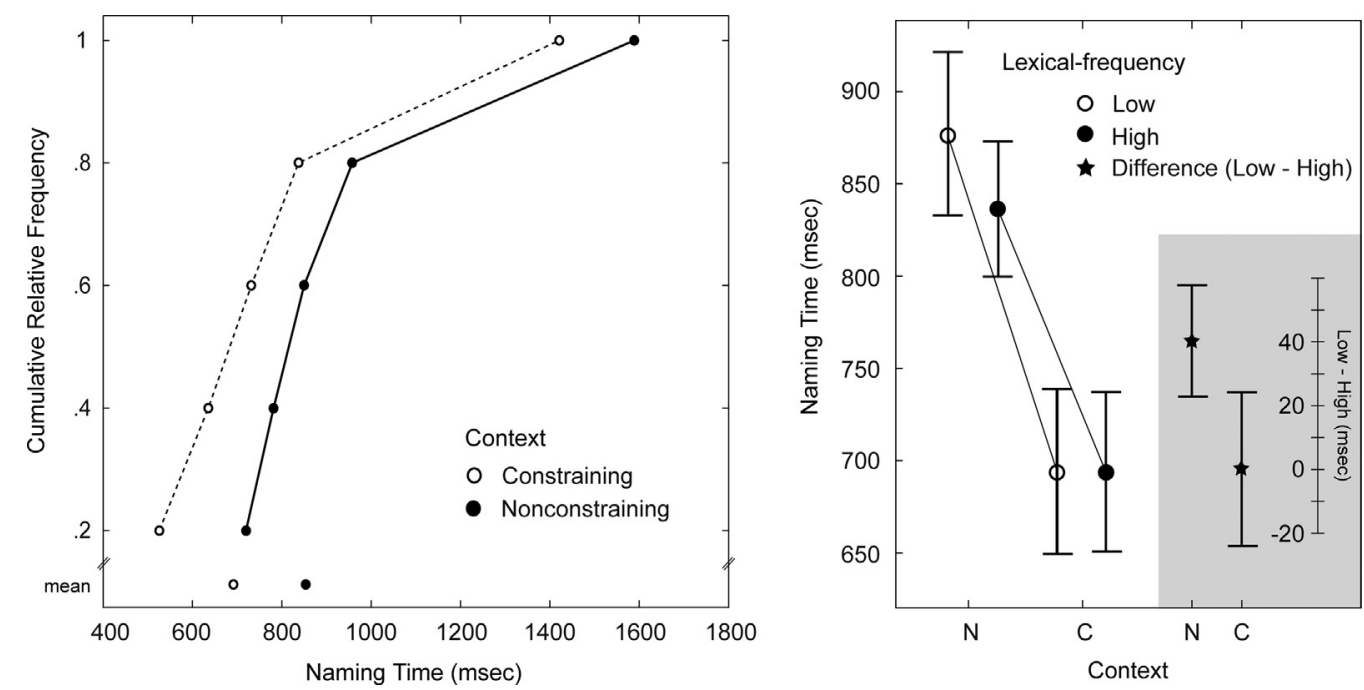

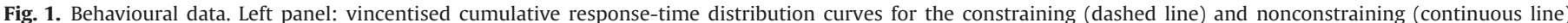

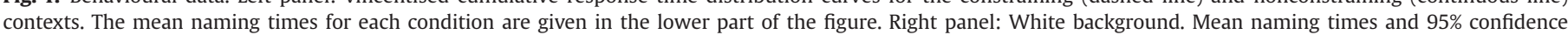

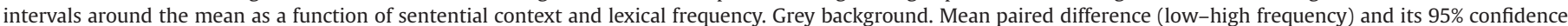
interval, whose zero is centred at the constraining context mean, as a function of context. $N=$ nonconstraining and $C=$ constraining. 
( $p=0.008$ ) that could be attributed to a spatio-temporal cluster of adjacent channels and time-points that exhibited a more negativegoing ERP amplitude in the constraining context than in the nonconstraining context. This cluster was detected between $16 \mathrm{~ms}$ pre-stimulus and $136 \mathrm{~ms}$ post-stimulus (left shaded area of Fig. 2) over the channels highlighted in white in the left topographical map. Additionally, a second statistically significant difference was detected between the constraining and nonconstraining contexts $(p=0.024)$ that could be attributed to a spatio-temporal cluster of adjacent channels and time-points that exhibited more positive-going ERPs for constraining than nonconstraining contexts. This cluster was detected between 270 and $386 \mathrm{~ms}$ (right shaded area of Fig. 2) over the channels highlighted in white in the right topographical map. Note that, contrary to common practice, here this effect is displayed as the difference for the constraining relative to the nonconstraining condition (i.e., portraying the effect as more positive-going for constraining than nonconstraining contexts rather than as more negative-going for nonconstraining than constraining contexts, like the effect of sentential constraint on the classic N400 effect in language comprehension studies). We did this to keep the ERP analysis consistent with our TFR analysis.

Using a cluster-based permutation approach that was frequency, time, and channel uninformed (Maris \& Oostenveld, 2007) while controlling for the false alarm rate, a statistically significant difference was revealed between the constraining and nonconstraining contexts that could be attributed to a spectrospatio-temporal cluster of adjacent frequencies, time-points, and channels that exhibited a similar difference between the constraining and nonconstraining conditions $(p<0.001)$. These results are shown in Fig. $3 \mathrm{~A}$, which presents the relative power decreases for the constraining relative to the nonconstraining context, and in Fig. 3B, where the significant cluster is indicated as highlighted activity at six different channels, whose position is shown to the right. The cluster was detected over the channels highlighted in black in the montage on the right of Fig. 3A. Power decreased for the constraining relative to the nonconstraining context in the $7-30 \mathrm{~Hz}$ alpha-beta range already in the interval prior to the presentation of the picture, roughly between $400 \mathrm{~ms}$ pre- to $200 \mathrm{~ms}$ post-picture onset. The effect was most prominent in left parietal electrodes, as shown in the scalp topography to the right in Fig. 3A. These findings indicate that desynchronisation in the alpha- and beta-bands with constraining relative to nonconstraining context already occurs before the picture is presented.

We addressed the progression of the power decreases for the context effect over the course of processing the sentence. The result is presented in Fig. 4 for the first two and last three words of the sentences and for the picture. As can be seen in the TFR panels, at the beginning of the sentence, there are no clear modulations in power as a function of context, neither for the first word $(p=0.700)$, nor for the second word of the sentence $(p=0.680)$. As the sentence develops, context starts modulating power for the third-to-last word of the sentence $(p=0.004)$ and for the secondto-last word $(p=0.035)$. These decreases occur between 400 and $600 \mathrm{~ms}$ after word presentation in the $8-15 \mathrm{~Hz}$ alpha range. At the last word before picture presentation, power modulations were also observed $(p<0.001)$. Here, power decreases in the $6-30 \mathrm{~Hz}$ alpha-beta range started already around $100 \mathrm{~ms}$ after word presentation. During picture presentation, power was also modulated $(p=0.003)$. For this cluster, the same scalp topography and frequency range is seen as for the last word pre-picture presentation, with power decreases lasting until about $300 \mathrm{~ms}$ after presentation of the picture. These findings indicate that the alpha-beta power decreases between 8 and $30 \mathrm{~Hz}$ observed as a function of sentential constraint (shown in Fig. 3) start no earlier
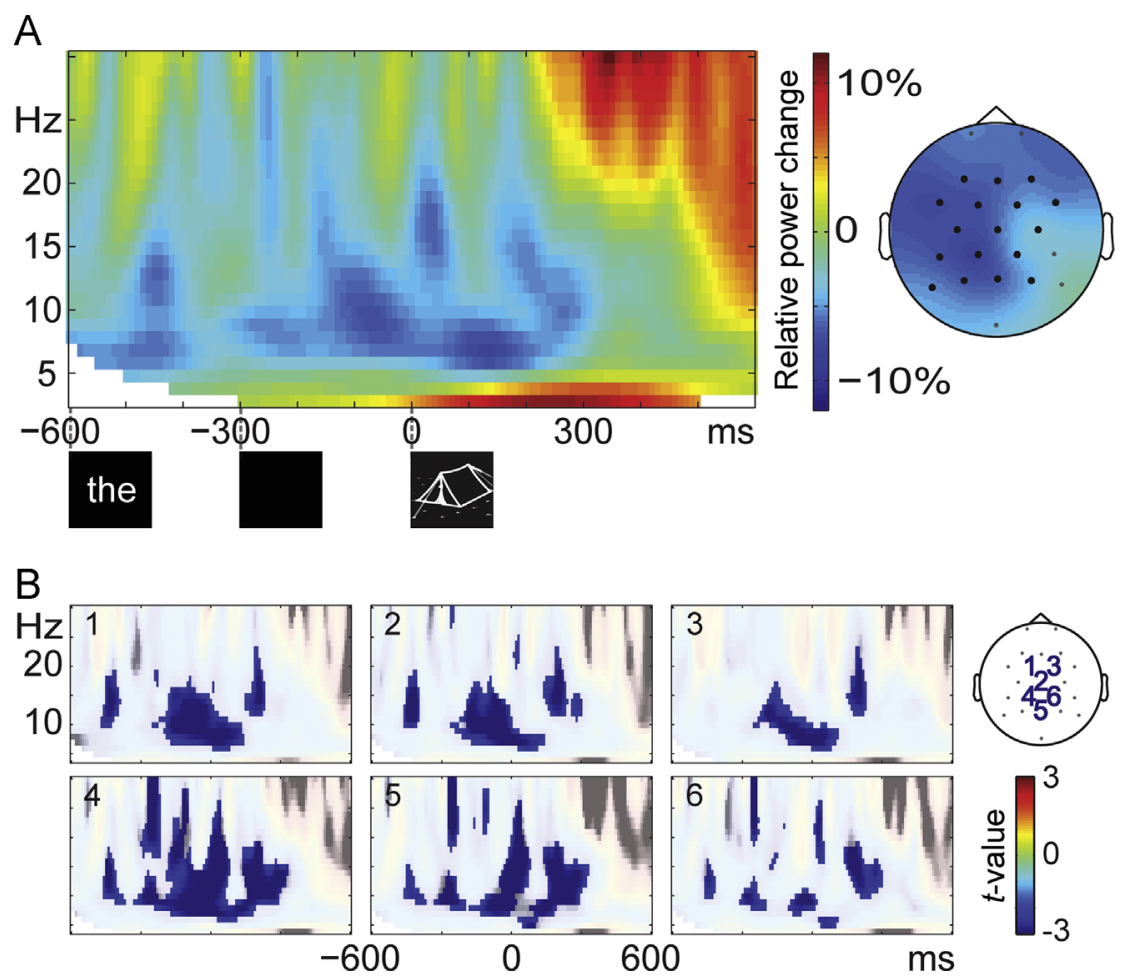

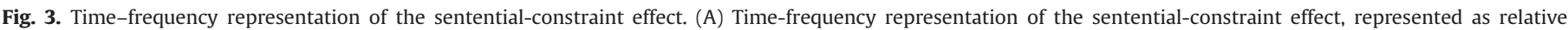

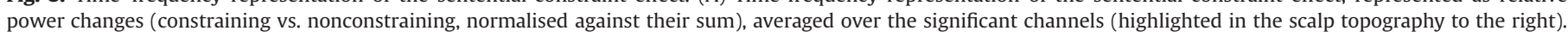

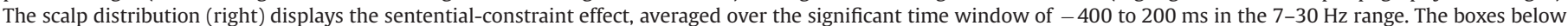
the figure exemplify the events in the trial. (B) Significant spectro-temporal clusters for the sentential-constraint effect at the six electrodes indicated on the right. 

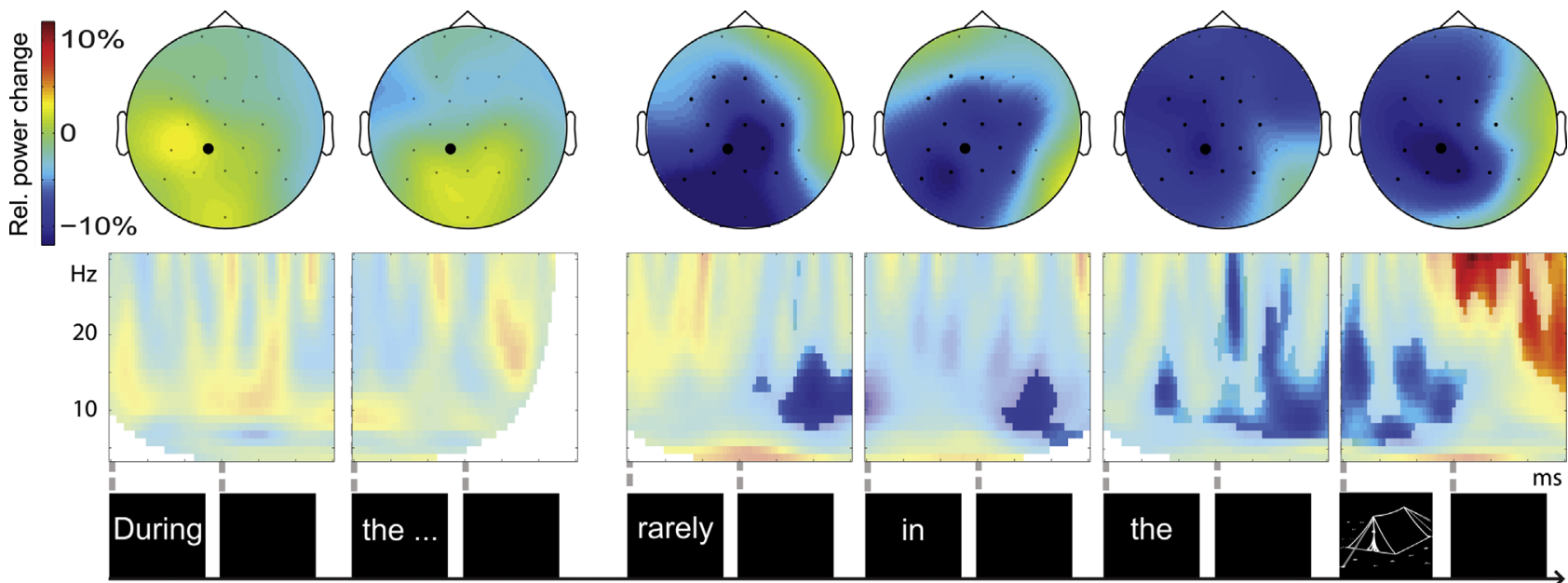

course of the sentence

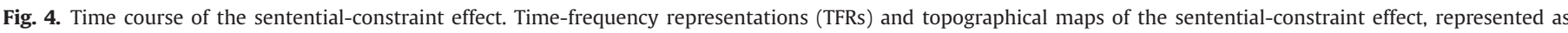

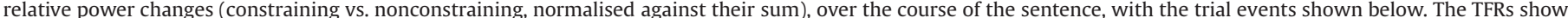

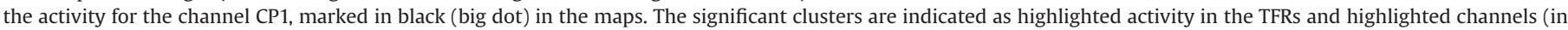

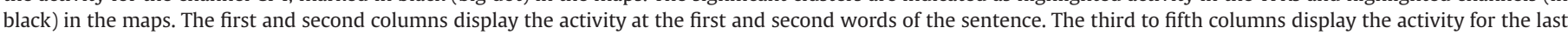
three words of the sentence before picture presentation. The last column displays the activity at picture presentation. Rel.=Relative.

than around the last word of the sentence preceding picture presentation.

\subsection{Lexical frequency differentially affects naming latencies and pre-picture theta-band power as a function of sentential context}

Fig. 1(right panel) presents the naming latencies as a function of context and lexical frequency (white background) and the mean paired difference between high- and low-frequency picture names (grey background). Naming responses were faster for high- than for low-frequency picture names, but only in the by-subject analysis, $F_{1}(1,14)=18.4, p<0.001, F_{2}(1,124)=1.7, p=0.190$. Context and lexical frequency interacted, $F_{1}(1,14)=5.4, p=0.036$, $F_{2}(1,124)=3.9, p=0.050$. Thus, the effect of lexical frequency was assessed for each context separately. Simple-effect analyses confirmed that the lexical-frequency effect was only present in the nonconstraining context, $F_{1}(1,14)=24.4, p<0.001, F_{2}(1,124)=4.3$, $p=0.039$, but not in the constraining context, $F s<1$. Additional analyses indicated that this effect is not confounded with differences in the number of phonemes between the picture names (see Supplement).

Using a cluster-based permutation approach with no a priori definition of time windows, frequencies, or channels (Maris \& Oostenveld, 2007), a statistically significant difference was revealed between the high-frequency and low-frequency conditions in the constraining context $(p=0.013)$. This difference was attributed to a spectro-spatio-temporal cluster of adjacent frequencies, time-points, and channels that exhibited a similar difference between the high-frequency and low-frequency conditions. These results are shown in Fig. 5A, which presents the relative power increases for the high-frequency relative to the low-frequency condition, and in Fig. 5B, where the significant cluster is indicated as highlighted activity at six different channels, whose position is shown to the right. The statistically significant cluster for the lexical-frequency effect in the constraining context was detected in the $4-10 \mathrm{~Hz}$ theta range, between $500 \mathrm{~ms}$ prepicture onset and $0 \mathrm{~ms}$ (picture onset), over the channels highlighted in black in the montage to the right of Fig. 5A. The effect was most prominent in parietal electrodes, as shown in the scalp topography to the right in Fig. 5A. Additional analyses indicated that this effect is not confounded with differences in the number of phonemes between the picture names (see Supplement). For the nonconstraining context, shown in Fig. 5C, no modulations of power were observed as a function of lexical frequency.

The grand-average ERPs for the lexical-frequency conditions are shown in Fig. 2, averaged over five representative channels (coloured red in the montage depicted on the left side of Fig. 2). No significant clusters were observed in the ERPs for the lexicalfrequency effect.

\section{Discussion}

In the present study, we investigated the electrophysiological signatures of lexical frequency and sentential constraint in spoken word production. Participants read sentences that were either contextually constraining or nonconstraining towards one target word. The last word of the sentence was presented as a picture that had to be named, and the picture name could be of high or low frequency.

\subsection{The effect of sentential constraint}

Our main findings for the context effect can be summarised as follows. In the naming responses, shorter latencies were observed for pictures following a constraining relative to a nonconstraining context, in line with previous literature (Griffin \& Bock, 1998), suggesting that the manipulation of context was successful in modulating the ease of word production. In the ERPs, a negativity was observed for constraining relative to nonconstraining context around picture presentation. Post-picture onset, the ERPs were more negative-going for nonconstraining relative to constraining context, in line with the classical N400 effect (Kutas \& Hillyard, 1980) in the language comprehension literature (see Kutas \& Federmeier, 2011).

In the TFRs, we observed decreases in alpha and beta power starting already before picture presentation for constraining relative to nonconstraining sentences. Specifically, at the third- and second-to-last words of the sentence, power decreased in the $8-15 \mathrm{~Hz}$ alpha range between 400 and $600 \mathrm{~ms}$ after word presentation, whereas at the last word before picture presentation and at picture presentation, the power decreases comprised a broader alpha-beta frequency range $(6-30 \mathrm{~Hz})$. Since the last word of the sentences was always either a determiner or an adjective 


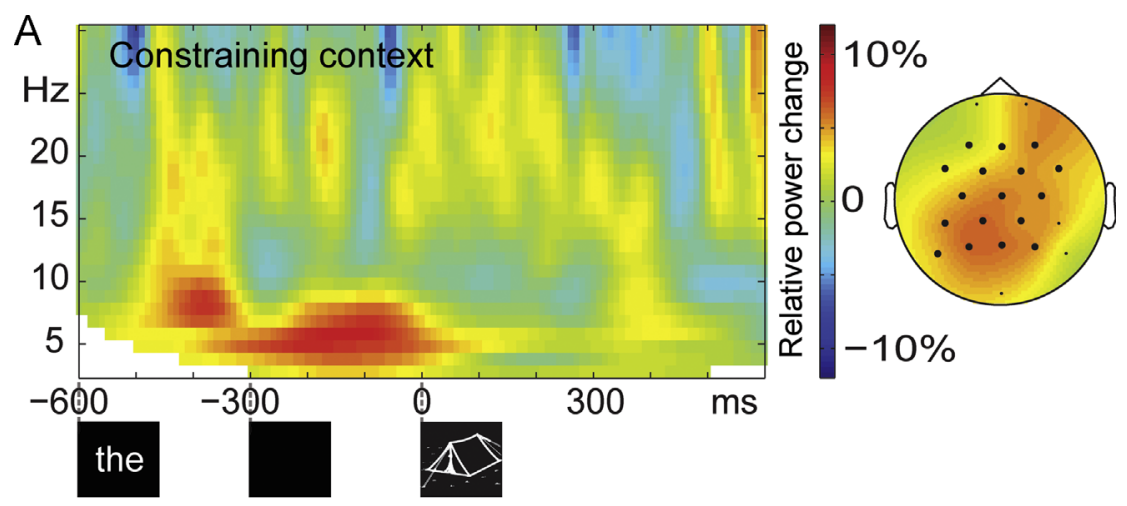

B
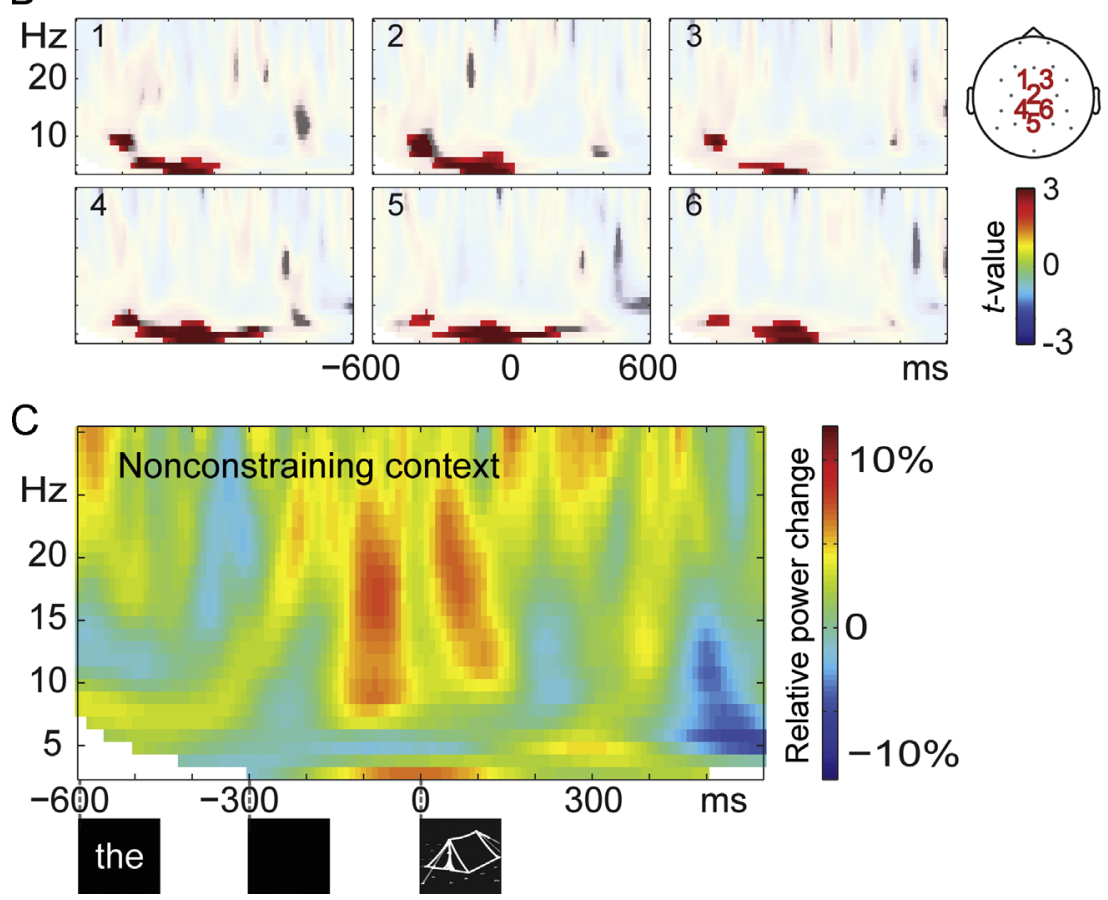

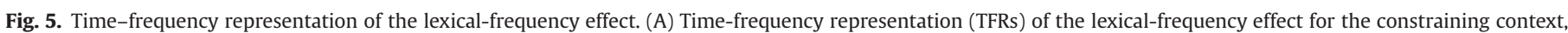

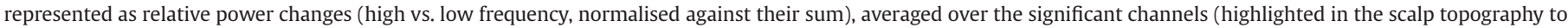

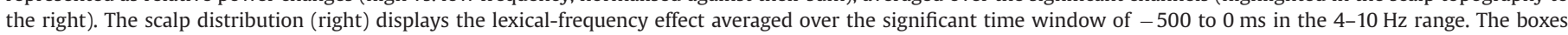

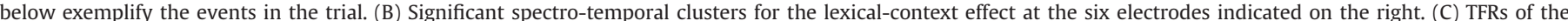

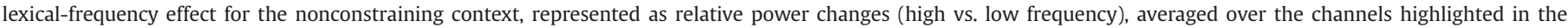
topographical map in A. The boxes below exemplify the events in the trial.

matched for lexical frequency and word length, we can be confident that the pre-picture effects (observed between $600 \mathrm{~ms}$ pre-picture onset to picture presentation) are not driven by differences in the word presented, but rather by differences in the sentential constraint as a whole.

\subsubsection{Alpha- and beta-power decreases}

It is well known that language users can anticipate linguistic material, even to the level of pre-activating (retrieving) specific words (for a review, see Kutas, DeLong, \& Smith, 2011). Evidence that access can begin already pre-picture presentation in our study is provided by the shorter naming latencies with constraining context and by the theta-band power modulations in the constraining context, which are discussed in Section 4.2.1 below. Accordingly, our pre-picture alpha-band activity may be related to (lexical) retrieval processes (e.g., Khader \& Rösler, 2011; Mellem et al., 2012) and to semantic memory (Klimesch, 1999; Klimesch et al., 1997; Röhm et al., 2001). However, this account is unlikely to be complete. Firstly, the lexical-frequency effect (a core index of memory processes) was associated with theta rather than alpha activity. Moreover, it has been shown that, when lexical-semantic prediction leads to the pre-activation of both visual word-forms and lexical representations, modulations in the theta band are observed (Dikker \& Pylkkänen, 2013). Furthermore, the alphaband activity was more prominent in a later time window ( $400 \mathrm{~ms}$ pre- to $200 \mathrm{~ms}$ post-picture presentation) than the theta-band activity (500 ms pre-picture to picture presentation). Of course, we cannot rule out the possibility that the alpha-band effects may also be reflecting lexical processing (e.g., Mellem et al., 2012), with different aspects of lexical access reflected in different frequency bands (see for similar proposals, e.g., Khader \& Rösler, 2011; Klimesch, Freunberger, Sauseng, \& Gruber, 2008; Klimesch, Freunberger, \& Sauseng, 2010; Mellem et al., 2012). Future research should be able to better clarify these issues.

Importantly, given that participants are in a setting in which they have to name pictures and, in many cases, they are able to predict the lexical item (the picture name), assembling the motor 
programme for articulation can also be initiated. Motor preparation and execution is known to be reflected in power decreases in the alpha and beta bands (e.g., Alegre et al., 2004; McFarland et al., 2000; Neuper et al., 2006; see for a review Cheyne, 2013), an account that would be in line with the present findings of alphaand beta-power decreases for constraining relative to nonconstraining contexts.

Alternatively, it could be argued that our alpha-power decreases relate to attention and sensory expectation of the upcoming visual stimulus, i.e., the picture (e.g., Klimesch, 1999; Klimesch et al., 1997; Klimesch, Doppelmayr, Russegger, Pachinger, \& Schwaiger, 1998; Van Ede et al., 2011, 2012). However, signal modulations due to expectation of a visual stimulus are commonly observed in the alpha band over occipital-parietal channels (e.g., Romei et al., 2010; Thut, Nietzel, Brandt, \& Pascual-Leone, 2006; Worden, Foxe, Wang, \& Simpson, 2000). This is consistent with only part of our observations: Only the modulations for the thirdand second-to-last words are in the alpha range $(8-15 \mathrm{~Hz})$ and have a mainly occipital-parietal scalp distribution (see Fig. 4). The power modulations around the last word (400 ms pre-picture onset), in turn, have a more fronto-central distribution and a wider spectrum $(6-30 \mathrm{~Hz})$, suggesting a process different from mere visual expectation. Thus, for now, we argue that our present alphaand beta-band activity may be better explained in terms of motor preparation for speaking, presumably including assembling the motor programme of the word to be produced.

\subsection{The effect of lexical frequency}

An important question addressed in the present study concerns the time at which contextual information can affect the access to lexical memory. The interaction between the lexical-frequency and sentential-context effects sheds light onto this issue. Naming latencies were shorter for pictures with high-frequency relative to low-frequency names only when the sentence context was nonconstraining, replicating Griffin and Bock (1998). Presumably, in a nonconstraining context, lexical access starts with the presentation of the picture, allowing for variables that affect the speed of access (e.g., lexical frequency; see Jescheniak \& Levelt, 1994; Kittredge et al., 2008), to be reflected in the naming latencies. In line with this hypothesis, with a nonconstraining context, no differences in the EEG as a function of lexical frequency were observed pre-picture onset.

With a constraining context, in turn, memory access can already be guided before the picture is presented, which would explain why an effect of lexical frequency is absent in the naming latencies (but see Griffin \& Bock, 1998). Naturally, if access of the picture name is initiated before picture presentation, an effect of lexical frequency should occur in a time window preceding the picture. This is indeed what we found in the oscillatory brain activity. In the TFRs of the constraining context, theta power increased for the high-frequency relative to the low-frequency picture names before picture presentation ( -500 to $0 \mathrm{~ms}$ ). This finding suggests that contextual constraints already guide the access of lexical representations for production before the presentation of the picture, that is, in the absence of the stimulus representing the target concept, contrary to what Griffin and Bock (1998) assumed.

For nonconstraining sentences, using a time- and channeluninformed analysis, we did not observe modulations of the ERPs as a function of lexical frequency ${ }^{1}$, a finding that is not in

${ }^{1}$ When using a time-informed test, constrained to $300-500 \mathrm{~ms}$ (e.g., Strijkers et al., 2011), a statistically significant cluster was detected for the lexical-frequency effect $(p=0.029$ ), with a more negative-going ERP amplitude in the low-frequency than in the high-frequency condition. agreement with previous reports of the lexical-frequency effect modulating ERP components (Laganaro et al., 2009; Strijkers et al., 2010). However, the paradigms used in these previous studies standard and delayed picture naming - were very different from our paradigm, so it remains difficult to directly compare these findings. Moreover, our study had fewer trials per lexicalfrequency condition relative to the other studies, which could also be a factor partly explaining the differences.

\subsubsection{Theta-band effects}

The observed theta-power modulations can be best interpreted as reflecting the access of lexical representations from long-term memory. This finding is in line with observations that, in the human neocortex, a clear relation exists between memory processes and theta-power changes (for reviews, see Düzel et al., 2010; Klimesch et al., 2010; Nyhus \& Curran, 2010). This result also agrees with the proposal from the language comprehension literature that a relation exists between the theta rhythm and the retrieval of lexical-semantic information (Bastiaansen et al. 2005, 2008).

The theta power increase for high-frequency relative to lowfrequency picture names merits further investigation. Increases in theta-band power in memory tasks have been previously associated with higher memory-trace strength relative to lower strength (e.g., Klimesch et al., 2006) and successful memory retrieval (i.e., correctly recognised old items versus correctly identified new items, e.g., Klimesch, Doppelmayr, Schwaiger Winkler, \& Gruber, 2000; Osipova et al., 2006), among others. Our findings can be explained by memory-trace strength (highfrequency words have a stronger memory trace) and retrieval success (high-frequency words may be easier to retrieve). Future investigations of memory retrieval in language production should be able to address these questions, which at the moment remain speculative.

\subsection{Differences between ERPs and oscillations}

In our study, the ERP effects were quite distinct from the oscillatory effects in both their time course and scalp topography (see also Davidson \& Indefrey, 2007; Laaksonen et al., 2012). These results highlight the possibility that these two types of measures are qualitatively different (see e.g., Davidson \& Indefrey, 2007; Laaksonen et al., 2012). In fact, the cue for access of the picture name in the two sentential contexts is quite different, i.e., either brought about by the presentation of a visual cue (the picture) representing the concept to be expressed (nonconstraining context) or driven by a slow build-up of converging conceptual information provided by the sentential context (constraining context). In this latter case, the converging conceptual information is not found consistently at a single point within the sentence, so over trials, lexical information is being retrieved at different points in time. This means that the access process will not be locked to a specific time point, and therefore, it is not reflected in the ERPs, which are by definition a measure of activity that is consistently locked to a specific time point. When the cue to retrieve lexical information is the picture, the access process is more likely to be consistently time locked over trials, resulting in an ERP response (e.g., Laganaro et al., 2009; Strijkers et al., 2010). This explanation is in line with the distinction between phase-locked (ERPs) and non-phase locked (oscillations) responses (Bastiaansen, Mazaheri, \& Jensen, 2012) and it could be more directly addressed by future language studies of memory access and retrieval comparing ERPs and oscillations. 


\subsection{Conclusions}

Using a task in which participants named pictures after reading sentences, we manipulated sentential constraint and lexical frequency, and assessed how these manipulations modulated ERPs and oscillatory brain responses. Our findings not only replicated previous behavioural findings on single word production, but also extended these findings to the domain of oscillations in relation to spoken word production in sentential context. We observed theta power increases before picture presentation for high- relative to low-frequency picture names only in constraining contexts, suggesting an electrophysiological marker of lexical access based solely on the contextual cues. Our electrophysiological data suggest that the interaction between lexical frequency and sentential constraint occurs already before picture onset, unlike what Griffin and Bock (1998) assumed. Furthermore, alpha- and beta-power decreases were observed around picture presentation for constraining relative to nonconstraining contexts, suggesting preparation of the speech motor-programme. Altogether, these results characterise the oscillatory brain responses induced by two fundamental factors affecting spoken word production, and point to possible avenues for studying the neurophysiological basis of spoken language production.

\section{Funding}

This research was supported by a grant from the Netherlands Organization for Scientific Research under Grant no. MaGW 40009-138 to Ardi Roelofs.

\section{Acknowledgements}

The authors thank the Center for Research in Language of the University of California, San Diego, for granting access to their picture database and Kristoffer Dahlslätt, Joost Rommers, the Language Division of the Donders Centre for Cognition, and the Neuronal Oscillations group of the Donders Centre for Cognitive Neuroimaging for helpful discussion.

\section{Appendix A. Supporting information}

Supplementary data associated with this article can be found in the online version at http://dx.doi.org/10.1016/j.neuropsychologia. 2013.11.014.

\section{References}

Alegre, M., et al. (2004). Frontal and central oscillatory changes related to different aspects of the motor process: A study in go/no-go paradigms. Experimental Brain Research, 159, 14-22.

Almeida, J., Finkbeiner, M., Knobel, M., \& Caramazza, A. (2007). The locus of the frequency effect in picture naming: When recognizing is not enough. Psychonomic Bulletin \& Review, 14, 1177-1182.

Aristei, S., Melinger, A., \& Abdel Rahman, R. (2011). Electrophysiological chronometry of semantic context effects in language production. Journal of Cognitive Neuroscience, 23, 1567-1586.

Baayen, R. H., Piepenbrock, R., \& van Rijn, H. (1993). The CELEX Lexical Database (CD-ROM).

Badecker, W., Miozzo, M., \& Zanuttini, R. (1995). The two-stage model of lexical retrieval: Evidence from a case of anomia with selective preservation of grammatical gender. Cognition, 57, 193-216.

Bastiaansen, M. C.M, \& Hagoort, P. (2003). Event-induced theta responses as a window on the dynamics of memory. Cortex, 39, 967-992.

Bastiaansen, M. C. M., Mazaheri, A., \& Jensen, O. (2012). Beyond ERPs: Oscillatory neuronal dynamics. In: S. J. Luck, \& E. S. Kappenman (Eds.), The Oxford handbook of event-related potential components (pp. 31-50). New York, NY: Oxford University Press.
Bastiaansen, M. C.M, van der Linden, M., Ter Keurs, M., Dijkstra, T., \& Hagoort, P. (2005). Theta responses are involved in lexical-semantic retrieval during language processing. Journal of Cognitive Neuroscience, 17, 530-541.

Bastiaansen, M. C. M., Oostenveld, R., Jensen, O., \& Hagoort, P. (2008). I see what you mean: Theta power increases are involved in the retrieval of lexical semantic information. Brain \& Language, 106, 15-28.

Blom, E., \& Vasić, N. (2011). The production and processing of determiner-noun agreement in child L2 Dutch. Linguistic Approaches to Bilingualism, 1, 265-290.

Bonin, P., Barry, C. Méot, A., \& Chalard, M. (2004). The influence of age of acquisition in word reading and other tasks: A never ending story? Journal of Memory and Language, 50, 456-476.

Buzsáki, G. (2006). Rhythms of the brain. USA: Oxford University Press.

Caramazza, A. (1997). How many levels of processing are there in lexical access? Cognitive Neuropsychology, 14, 177-208.

Caramazza, A., \& Hillis, A. E. (1989). The disruption of sentence production: Some dissociations. Brain and Language, 36, 625-650.

Chen, C-C., et al. (2012). A dynamic causal model for evoked and induced responses. NeuroImage, 59, 340-348.

Cheyne, D. (2013). MEG studies of sensorimotor rhythms. A review. Experimental Neurology, 245, 27-39.

Cholin, J., Dell, G. S., \& Levelt, W. J. M. (2011). Planning and articulation in incremental word production: Syllable-frequency effects in English. Journal of Experimental Psychology: Learning Memory and Cognition, 37, 109-122.

Davidson, D. J., \& Indefrey, P. (2007). An inverse relation between event-related and time-frequency violation responses in sentence processing. Brain Research, $1158,81-92$.

Dell, G. S. (1986). A spreading-activation theory of retrieval in sentence production. Psychological Review, 93, 283-321.

Dikker, S., \& Pylkkänen, L. (2013). Predicting language: MEG evidence for lexical preactivation. Brain \& Language, 127, 55-64.

Donner, T. H., \& Siegel, M. (2011). A framework for local cortical oscillation patterns. Trends in Cognitive Sciences, 15, 191-199.

Düzel, E., Penny, W. D., \& Burgess, N. (2010). Brain oscillations and memory. Current Opinion in Neurobiology, 20, 143-149.

Engel, A. K., \& Fries, P. (2010). Beta-band oscillations-signalling the status quo? Current Opinion in Neurobiology, 20, 156-165.

Engel, A. K., Fries, P., \& Singer, W. (2001). Dynamic predictions: Oscillations and synchrony in top-down processing. Nature Reviews Neuroscience, 2, 704-716.

Eulitz, C., Hauk, O., \& Cohen, R. (2000). Electroencephalographic activity over temporal brain areas during phonological encoding in picture naming. Clinical Neurophysiology, 111, 2088-2097.

Ewald, A., Aristei, S., Nolte, G., \& Abdel-Rahman, R. (2012). Brain oscillations and functional connectivity during overt language production. Frontiers in Psychology, 3, 166.

Ganushchak, L. Y., Christoffels, I. K., \& Schiller, N. O. (2011). The use of electroencephalography in language production research: A review. Frontiers in Psychology, 2, 208

Gollan, T. H., et al. (2011). Frequency drives lexical access in reading but not in speaking: the frequency-lag hypothesis. Journal of Experimental Psychology: General, 140, 186-209.

Griffin, Z. M., \& Bock, K. (1998). Constraint, word frequency, and the relationship between lexical processing levels in spoken word production. Journal of Memory and Language, 38, 313-338.

Hanslmayr, S., Staudigl, T., \& Fellner, M-C. (2012). Oscillatory power decreases and long-term memory: The information via desynchronization hypothesis. Frontiers in Human Neuroscience, 6, 74

Hickok, G. (2012). Computational neuroanatomy of speech production. Nature Reviews Neuroscience, 13, 135-145.

Indefrey, P. (2011). The spatial and temporal signatures of word production components: A critical update. Frontiers in Psychology, 2, 255.

Indefrey, P., \& Levelt, W. J. M. (2004). The spatial and temporal signatures of word production components. Cognition, 92, 101-144.

Jacobs, J., Hwang, G., Curran, T., \& Kahana, M. J. (2006). EEG oscillations and recognition memory: Theta correlates of memory retrieval and decision making. Neurolmage, 32, 978-987.

Jensen, O., \& Mazaheri, A. (2010). Shaping functional architecture by oscillatory alpha activity: Gating by inhibition. Frontiers in Human Neuroscience, 4, 186.

Jescheniak, J. D., \& Levelt, W. J. M. (1994). Word frequency effects in speech production: Retrieval of syntactic information and of phonological form. Journal of Experimental Psychology: Learning, Memory, and Cognition, 20, 824-843.

Khader, P. H., \& Rösler, F. (2011). EEG power changes reflect distinct mechanisms during long-term memory retrieval. Psychophysiology, 48, 362-369.

Kittredge, A. K., Dell, G. S., Verkuilen, J., \& Schwartz, M. F. (2008). Where is the effect of frequency in word production? Insights from aphasic picture-naming errors. Cognitive Neuropsychology, 25, 463-492.

Klimesch, W. (1997). EEG-alpha rhythms and memory processes. International Journal of Psychophysiology, 26, 319-340.

Klimesch, W. (1999). EEG alpha and theta oscillations reflect cognitive and memory performance: a review and analysis. Brain Research Reviews, 29, 169-195.

Klimesch, W., Doppelmayr, M., Pachinger, T., \& Russegger, H. (1997). Event-related desynchronization in the alpha band and the processing of semantic information. Cognitive Brain Research, 6, 83-94.

Klimesch, W., Doppelmayr, M., Russegger, H., Pachinger, T., \& Schwaiger, J. (1998). Induced alpha band power changes in the human EEG and attention. Neuroscience Letters, $244,73-76$. 
Klimesch, W., Doppelmayr, M., Schwaiger, J., Winkler, T., \& Gruber, W. (2000). Theta oscillations and the ERP old/new effect: Independent phenomena? Clinical Neurophysiology, 111, 781-793.

Klimesch, W., et al. (2006). Oscillatory EEG correlates of episodic trace decay. Cerebral Cortex, 16, 280-290.

Klimesch, W., Freunberger, R., Sauseng, P., \& Gruber, W. (2008). A short review of slow phase synchronization and memory: Evidence for control processes in different memory systems? Brain Research, 1235, 31-44.

Klimesch, W., Freunberger, R., \& Sauseng, P. (2010). Oscillatory mechanisms of process binding in memory. Neuroscience and Biobehavioral Reviews, 34, 1002-1014.

Kutas, M., \& Federmeier, K. D. (2011). Thirty years and counting: Finding meaning in the N400 component of the event-related brain potential ERP. Annual Review of Psychology, 62, 621-647.

Kutas, M., \& Hillyard, S. A. (1980). Reading senseless sentences: Brain potentials reflect semantic incongruity. Science, 207, 203-205.

Kutas, M., DeLong, K., \& Smith, N. (2011). A look around at what lies ahead: Prediction and predictability in language processing. In: M. Bar (Ed.), Predictions in the brain: using our past to generate a future (pp. 190-207). Oxford University Press.

Laaksonen, H., Kujala, J., Hultén, A., Liljeström, M., \& Salmelin, R. (2012). MEG evoked responses and rhythmic activity provide spatiotemporally complementary measures of neural activity in language production. Neurolmage, 60, 29-36.

Laganaro, M., et al. (2009). Electrophysiological correlates of different anomic patterns in comparison with normal word production. Cortex, 45, 697-707.

Laganaro, M., Valente, A., \& Perret, C. (2012). Time course of word production in fast and slow speakers: A high density ERP topographic study. Neurolmage, 59, 3881-3888.

Levelt, W. J. M. (1989). Speaking: from intention to articulation. Cambridge: MIT Press.

Levelt, W. J. M., Roelofs, A., \& Meyer, A. S. (1999). A theory of lexical access in speech production. Behavioral and Brain Sciences, 22, 1-75.

Maris, E., \& Oostenveld, R. (2007). Nonparametric statistical testing of EEG- and MEG-data. Journal of Neurosciences Methods, 164, 177-190.

McFarland, D. J., Miner, L. A., Vaughan, T. M., \& Wolpaw, J. R. (2000). Mu and beta rhythm topographies during motor imagery and actual movements. Brain Topography, 12, 177-186.

Mellem, M. S., Bastiaansen, M. C. M., Pilgrim, L. K., Medvedev, A. V., \& Friedman, R B. (2012). Word class and context affect alpha-band oscillatory dynamics in an older population. Frontiers in Psychology, 3, 97.

Moors, A., et al. (2013). Norms of valence, arousal, dominance, and age of acquisition for 4,300 Dutch words. Behavior Research Methods, 45, 169-177.

Monaco, J. D., Abbott, L. F., \& Kahana, M. J. (2007). Lexico-semantic structure and the word-frequency effect in recognition memory. Learning $\mathcal{E}$ Memory, 14, 204-213.

Neuper, C., Wörtz, M., \& Pfurtscheller, G. (2006). ERD/ERS patterns reflecting sensorimotor activation and deactivation. Progress in Brain Research, 159, $211-222$.

Nunez, P. L., \& Srinivasan, R. (2006). Electric fields of the brain: the neurophysics of EEG (2nd ed.). New York: Oxford University Press.

Nyhus, E., \& Curran, T. (2010). Functional role of gamma and theta oscillations in episodic memory. Neuroscience and Biobehavioral Reviews, 347, 1023-1035.

Oldfield, R., \& Wingfield, A. (1965). Response latencies in naming objects. Quarterly Journal of Experimental Psychology, 17, 273-281.

Oostenveld, R., Fries, P., Maris, E., \& Schoffelen, J-M. (2011). FieldTrip: Open source software for advanced analysis of MEG, EEG, and invasive electrophysiological data. Computational Intelligence and Neuroscience, 2011, 1-9.

Osipova, D., et al. (2006). Theta and gamma oscillations predict encoding and retrieval of declarative memory. Journal of Neuroscience, 26, 7523-7531.
Piai, V., Roelofs, A., \& van der Meij, R. (2012). Event-related potentials and oscillatory brain responses associated with semantic and Stroop-like interference effects in overt naming. Brain Research, 1450, 87-101.

Piai, V., Roelofs, A., Jensen, O., Schoffelen, J-M., \& Bonnefond, M. (2013). Distinct patterns of brain activity characterize lexical activation and competition in speech production. Manuscript submitted for publication.

Ratcliff, R. (1979). Group reaction time distributions and an analysis of distribution statistics. Psychological Bulletin, 86, 446-461.

Roelofs, A. (1992). A spreading-activation theory of lemma retrieval in speaking. Cognition, 42, 107-142.

Roelofs, A. (1997). The WEAVER model of word-form encoding in speech production. Cognition, 64, 249-284.

Roelofs, A. (1998). Rightward incrementality in encoding simple phrasal forms in speech production: Verb-particle combinations. Journal of Experimental Psychology: Learning, Memory, and Cognition, 24, 904-921.

Röhm, D., Klimesch, W., Haider, H., \& Doppelmayr, M. (2001). The role of theta and alpha oscillations for language comprehension in the human electroencephalogram. Neuroscience Letters, 310, 137-140.

Romei, V., Gross, J., \& Thut, G. (2010). On the role of prestimulus alpha rhythms over occipito-parietal areas in visual input regulation: Correlation or causation? Journal of Neuroscience, 30, 8692-8697.

Schroeder, C. E., \& Lakatos, P. (2009). Low-frequency neuronal oscillations as instruments of sensory selection. Trends in Neurosciences, 32, 9-18.

Severens, E., Van Lommel, S., Ratinckx, E., \& Hartsuiker, R. J. (2005). Timed picture naming norms for 590 pictures in Dutch. Acta Psychologica, 119, 159-187.

Strijkers, K., Costa, A., \& Thierry, G. (2010). Tracking lexical access in speech production: Electrophysiological correlates of word frequency and cognate effects. Cerebral Cortex, 20, 912-928.

Strijkers, K., Holcomb, P. J., \& Costa, A. (2011). Conscious intention to speak proactively facilitates lexical access during overt object naming. Journal of Memory and Language, 65, 345-362.

Szekely, A., et al. (2004). A new on-line resource for psycholinguistic studies Journal of Memory and Language, 51, 247-250.

Taylor, W. L. (1953). Cloze procedure: A new tool for measuring readability. Journalism Quarterly, 30, 415-433.

Thut, G., Nietzel, A., Brandt, S. A., \& Pascual-Leone, A. (2006). Alpha-Band electroencephalographic activity over occipital cortex indexes visuospatial attention bias and predicts visual target detection. Journal of Neuroscience, 26 , 9494-9502.

Uhlhaas, P. J., Roux, F., Rodriguez, E., Rotarska-Jagiela, A., \& Singer, W. (2010). Neural synchrony and the development of cortical networks. Trends in Cognitive Sciences, 14, 72-80.

Ullman, M. T. (2001). A neurocognitive perspective on language: The declarative/ procedural model. Nature Reviews Neuroscience, 2, 717-726.

Van Casteren, M., \& Davis, M. H. (2006). Mix, a program for pseudorandomization. Behavior Research Methods, 38, 584-589.

Van Ede, F., de Lange, F. P., Jensen, O., \& Maris, E. (2011). Orienting attention to an upcoming tactile event involves a spatially and temporally specific modulation of sensorimotor alpha- and beta-band oscillations. Journal of Neuroscience, 31 2016-2024.

Van Ede, F., de Lange, F. P., \& Maris, E. (2012). Attentional cues affect accuracy and reaction time via different cognitive and neural processes. Journal of Neuroscience, 32, 10408-10412.

Willems, R. M., Oostenveld, R., \& Hagoort, P. (2008). Early decreases in alpha and gamma band power distinguish linguistic from visual information during spoken sentence comprehension. Brain Research, 1219, 78-90.

Worden, M. S., Foxe, J. J., Wang, N., \& Simpson, G. V. (2000). Anticipatory biasing of visuospatial attention indexed by retinotopically specific alpha-band electroencephalography increases over occipital cortex. Journal of Neuroscience, 20, 1-6. 